\title{
Determinants of Utilization of Nursing Process Among Nurses in University College Hospital, Ibadan, Oyo State, Nigeria
}

\author{
Soyinka Oyinkansola Zainab Prof. R. O Salawu \\ Department of Adult Health, School of Nursing, Babcock University Ilishan- Remo, \\ Ogun State, Nigeria
}

\begin{abstract}
Poor utilization of nursing process can lead to poor quality of nursing care, disorganizarion of the service, conflicting roles, medication error, poor diseases prognosis, readmission, dissatisfaction with the care provided and increased mortality. Therefore, this study assessed determinants of nursing process utilization in University College Hospital (UCH), Ibadan. This study adopted a descriptive research design. A multi-stage sampling technique was adopted to select 296 respondents from all the thirty-two (32) wards at UCH while the sample size was determined using Slovin's formula. Data were collected using the self-structured questionnaire developed by the researcher for the purpose of this study. Five research questions were raised to guide this study and tested at 0.05 level of significance using of simple percentages and Multiple Regression Analysis. The findings indicated that knowledge level of nurses on nursing process was high and adequate $(86.3 \%)$ while nurses' utilization of nursing process was $56.2 \%$. This study showed that attitudinal $\left(\mathrm{R}=.347, \mathrm{R}^{2}=.120\right.$, Adj. $\mathrm{R}^{2}=.117, \mathrm{f}_{(1,277)}=$ 37.797; $\mathrm{P}=.000)$, institutional $\left(\mathrm{R}=.285, \mathrm{R}^{2}=.081\right.$, Adj. $\left.\mathrm{R}^{2}=.078, \mathrm{f}_{(1,277)}=37.797 ; \mathrm{P}=.000\right)$ and nurses' knowledge of nursing process $\left(\mathrm{R}=.194, \mathrm{R}^{2}=.038\right.$, Adj. $\left.\mathrm{R}^{2}=.034, \mathrm{f}_{(1,277)}=10.830 ; \mathrm{P}=.001\right)$ are determinants of the utilization of nursing process among nurses. Also, the nurses' age, gender, professional qualifications, professional cadre, and years of working experience failed to significantly influence the utilization of nursing process. The study concluded that nurses' knowledge, attitude and institutional factors are core issues in the proper utilization of nursing process. Therefore, Effective and efficient implementation of the nursing process directly contributes to the quality of healthcare and the patients' health outcomes.
\end{abstract}

Keywords: Determinants, nursing process, utilization

DOI: $10.7176 / \mathrm{JHMN} / 70-05$

Publication date: January $31^{\text {st }} 2020$

\section{Introduction}

Utilization of nursing process results in the formation of a strong nurse-patient relationship. This will promote the patient's compliance to the treatment regimen, hence good care outcome. However, despite the universal benefits of the nursing process, its utilization has remained minimal in health care facilities in Nigeria. Poor utilization of the nursing process may lead to poor quality of patient care and nursing care. However, nurses' ability to utilize nursing process may be affected by many factors, therefore, the determinants of nursing process utilization need to be understood so as to form the yardstick for providing solutions that will enhance its utilization in the clinical practice of nurses and also to provide insight to the setbacks and obstacles that prevent the nurses from practicing with their trademark of autonomy which is the nursing process.

A cross-sectional retrospective study carried out to review 302 records for adult patients admitted to surgical clinical and intensive care unit in a hospital in Porto Alegres showed that deficiency in data collection for nursing records and absence of the nursing diagnosis steps were the major findings in this study, therefore, their absence showed that there was poor utilization of the nursing process among the study participants (Pokorski, Moraes, Chiarelli, Costanzi \& Rabelo, 2009). Similarly, a study involving 200 nurses showed that all respondents never followed the scientific ways of applying nursing process while providing care to patients. These findings correspond to those realized in a study to evaluate utilization of nursing process among nurses in a Psychiatric hospital in Port Harcourt (Nigeria)whereby the nurses' practice on nursing process was found to be poor (Afolayan, Donald, Baldwin, Onasoga \& Babafemi, 2013). Likewise, a review of 68 medical records at a Brazilian teaching hospital showed that all the steps of nursing process were not documented (Lopes, Higa, Christoforo, Oliveira \& Reis, 2010). These findings were in concurrence with those of a study on professional nurses' perception of the nursing process at the University of Calabar Teaching Hospital, Nigeria which showed that $62.7 \%$ of the respondents were constantly using the NANDA diagnostic system, with $25.4 \%$ using it occasionally while $11.9 \%$ never used it at all. Another study conducted among 249 nurses from five selected health care facilitiesin Kenya, the study results showed that utilization of nursing process among the respondents was poor (Mbithi, Mwenda, \& Karonjo, 2018)

Nursing process is a systematic problem-solving approach used to identify, prevent and treat actual or potential health problems and promote wellness. It consists of five steps which are assessment, diagnosis, planning, implementation, and evaluation (Aseratie, Murugan, \& Molla, 2014). Nursing process is the major way to render quality nursing care to patients. The utilization of nursing process to everyday practice results in 
elevated standards of nursing care, increased quality of nursing care as well as personal and professional growth for nurses. Additionally, using nursing process in practice not only benefits patients, but also strengthens nursing as a profession. Using the nursing process as a tool to guide care provided to patients will allow nurses to autonomously make some decisions that can promote healing.

According to Ojo (2010) one of the components of best practices in nursing care is the implementation of a process of assessment of clients/patients' condition, formulating nursing diagnosis, identifying outcomes, planning care, implementing nursing interventions and evaluating care. The nursing process provides an organized framework to guide nursing practice. It is a problem solving method, which is client focused, hence the client becomes an active participant. It provides an individualized, orderly and systematic method for planning and providing care. It enhances nursing efficiency by standardizing nursing practice. The process facilitates documentation of care and provides a unified language for the profession of nursing. It emphasizes the independent function of professional nurses and promotes personal satisfaction as clients' goals are achieved. The process also enhances professional growth as nurses evaluate effectiveness of their interventions (Agunwah, 2010).

In order to achieve quality of health care service, quality of nursing care is the key element and the utilization of nursing process has a significant role, but, in practice, utilization of the nursing process is not well developed (Donkor, 2009).According to Ojo (2010), the implementation of the nursing process in patient care in Nigeria is very low. The authors identified poor attitudes of senior nursing sisters and matron as part of the constraints to its full implementation in Obafemi Awolowo University Teaching Hospitals Complex, Ile-Ife, Osun state, Nigeria. Ofi, Sowunmi, Edet and Anarado (2008) also observed that the nursing process was not fully implemented on all the wards and units of the Obafemi Awolowo University Teaching Hospital, in the wards where it is implemented, not every patient admitted in the hospital is nursed using the nursing process.

A study carried out in Ethiopia (2017) on nursing process implementation and associated factors among nurses identified different factors which affect the implementation of the nursing process in hospitalized setting. Institutional factors like organizational structure and facilities in both material and human resources are one of the categories of factors that affect the implementation of nursing process, the other category of factors is nursing factors for example knowledge factors, especially for formulation of nursing diagnosis in developing nursing care plans, skills, experience; attitude factors such as interest and beliefs of nurses on importance of nursing process and these greatly affect the implementation (Baraki, Girmay, Kidanu, Gerensea, Gezehgne \& Teklay, 2017). A study carried out by Abebe, Abera \& Ayana (2014) showed that the implementation of the nursing diagnosis is a challenge for nurses.

A study conducted by Lee (2005) on factors influencing the implementation of nursing process indicated that knowledge factor, institutional factor, professional factor/attitudinal factor were factors that resulted in the non-implementation of the nursing process as it ought to be. An investigation of the steps of the nursing process actually implemented in the routine of a university hospital showed that all phases were performed however; problems were identified in the utilization of nursing process in the aspects of documentation of patients' history and implementation of nursing interventions. The evaluation of expected results, in particular, was not adequately recorded (Abebe, et al., 2014). Also, a study carried out in Nigeria by Ofi et al. (2008) indicated that nurses implemented the nursing process $40.37 \%, 13.76 \%, 43.12 \%$ and $2.75 \%$ at the level of assessment, level of nursing diagnosis, nursing care plan, and evaluation respectively. The variation of the result may be due to differences in the study sited, the progress of the nursing profession, resources and technological variations, government commitment, level of nursing practice and lack of clear nursing standard.

A study conducted by Adeyemo and Olaogun, (2013) in Nigeria on factors influencing the implementation of nursing process indicated that knowledge factor has the highest predictive value in the use of nursing process, followed by institutional factor and professional factor, the least is the attitude factor. The result concluded that the knowledge factor has the most important influence on the use of nursing process. Study carried out in Ethiopia (2017) shows that Seventy (35\%) of the participants have implemented nursing process. Different factors showed significant association. Nurses who worked in a stressful atmosphere of the workplace were $99 \%$ less likely to implement the nursing process than nurses who worked at a very good atmosphere. The nurses with an educational level of BNSc. Degree were 6.972 times more likely to implement the nursing process than those who were diploma qualified. Also, nurses with no consistent material supply to use for the nursing process were 95.1\% less likely to implement the nursing process than nurses with consistent material supply (Baraki et al., 2017).

According to Pokorski, Moraes, Chiarelli, Costanzi and Rabelo, (2009), the factors affecting utilization of nursing process among nurses is lack of knowledge of the steps involved in the process, excessive number of tasks assigned to the nursing team, poor quality of professional education and insufficient reports on physical examination related to the disease. They also reported that the militating institutional factor includes hospital policy and its effect on utilization of nursing process, non- availability of necessary facilities and excessive number of tasks assigned to the nursing team or excess workload. Similar study carried out by Akpan-idiok, 
(2017) showed nurses do not carry out nursing process due to lack of time, excess workload, repetitious replacement of the nurses, and no nursing process booklet or stationeries.

One strategy to increase nursing process utilization in practice is to identify barriers to nursing process utilization. However, there had been few research in Nigeria conducted to examine those barriers. Hence, the need to identify the determinants of nursing process utilization among nurses in University College Hospital (UCH), Ibadan, Oyo state, Nigeria.

\section{Research Questions}

1. What is the level of nursing process utilization among nurses in University College Hospital (UCH), Ibadan?

2. What is the level of knowledge about nursing process among nurses in University College Hospital (UCH), Ibadan?

3. What is the influence of nurses' socio-demographic characteristics (age, gender, professional qualifications, professional cadre, and years of working experience) on nursing process utilization among nurses in University College Hospital, (UCH), Ibadan?

4. What is the influence of attitudinal factors on nursing process utilization among nurses in University College Hospital (UCH), Ibadan?

5. What is the influence of institutional factors on nursing process utilization among nurses working in University College Hospital (UCH), Ibadan?

\section{Methodology}

Research Design: A descriptive research design will be utilized to assess the determinants of nursing process utilization among nurses in University College Hospital, Ibadan, Oyo state, Nigeria.

Population: The study population consist of nurses in all the thirty-two (32) wards in University College Hospital (UCH). The total number of nurses in these wards are 796. Thus the population for the study is 796 . The statistics were obtained from the office of the Assistant Director of Nursing of each of the wards.

Sampling Technique and sample size determination: The total number of units in University College Hospital $(\mathrm{UCH})$ are nine, encompassing thirty-two (32) wards with total number of 796 nurses. Thus, a multi-stage sampling technique was adopted. Firstly, all the thirty-two (32) wards at UCH were stratified into nine existing units. The sample size was determined using Slovin's formula. Therefore, the sample size for this study is 296. Secondly, Proportional allocation was done to select the number of nurses that participated in the study from each unit. Thirdly, simple random sampling technique was adopted to select the participants in other to prevent any form of bias.

Research Instrument: The researcher designed a questionnaire to gather data for this study. The questionnaire consists of five sections. The questionnaire was structured in a way that enabled respondents to select from the options provided. The reliability was tested out among 30 nurses in Babcock University, Ilishan-Remo, Ogun State using a split-half method. The questionnaire a reliability coefficient of .88 .

Procedure for Data Collection: The researcher obtained ethical clearance from ethical committee of UI/UCH (IAMRAT) in order to collect data. The researcher visited all the thirty-two wards in UCH and collected data from the Assistant Directors of Nursing (ADN) or Deputy Directors of Nursing (DDN) of each wards about the number of nurses in the wards and the units in which they are categorized. The questionnaires were distributed to the participant of this study after they have been informed of the purpose of the study and due permission have been gotten. Data collection would be done over a period of two (2) weeks. The questionnaires were given to respondents who satisfy the inclusion criteria and retrieved on the spot. Confidentiality and anonymity will be guaranteed.

Method of Data Analysis: Data obtained was checked for errors and completeness. Descriptive statistics (frequency counts, percentages, mean, standard deviation) and simple regression were used to analyse the data. 


\section{Result}

Table 1: Knowledge of Nurses about Nursing Process

\begin{tabular}{|c|c|c|c|c|c|}
\hline $\mathrm{s} / \mathrm{n}$ & Items & Yes & $\%$ & No & $\%$ \\
\hline 1 & Nursing process is a foundation of nursing practice & 256 & 92.1 & 22 & 7.9 \\
\hline 2 & $\begin{array}{l}\text { Nursing process is the systematic collection of patient care data for } \\
\text { determining nursing care needs and evaluating patient's care outcome }\end{array}$ & 278 & 100 & - & - \\
\hline 3 & $\begin{array}{l}\text { The central purpose of nursing process is to diagnose and treat human } \\
\text { responses to actual and potential health problems. }\end{array}$ & 275 & 98.9 & 3 & 1.1 \\
\hline 4 & Only critical cases should be nursed using the nursing process & 19 & 6.8 & 259 & 93.1 \\
\hline 5 & The nursing process has six steps & 216 & 77.7 & 62 & 22.3 \\
\hline 6 & $\begin{array}{l}\text { Assessment in nursing process is to find out actual and potential problems } \\
\text { facing patients. }\end{array}$ & 275 & 98.9 & 3 & 1.1 \\
\hline 7 & $\begin{array}{l}\text { Nursing diagnosis is expressed as the concise statement of the problem, stating } \\
\text { its relation to pathophysiology in the given situation and stating the way it is } \\
\text { displayed/manifested by patient as evidenced by }\end{array}$ & 275 & 98.9 & 3 & 1.1 \\
\hline 8 & $\begin{array}{l}\text { Outcome identification/planning phase in nursing process establishes goals } \\
\text { and expected outcomes which provides guidelines for individualized nursing } \\
\text { interventions. }\end{array}$ & 269 & 96.8 & 9 & 3.2 \\
\hline 9 & $\begin{array}{l}\text { Implementation phase in nursing process is the performance of nursing } \\
\text { interventions that is identified during the planning phase }\end{array}$ & 264 & 95.0 & 14 & 5.0 \\
\hline 10 & $\begin{array}{l}\text { Evaluation is the final step of nursing process that determines whether the } \\
\text { client goals have been met, partially met or not met. }\end{array}$ & 272 & 97.8 & 6 & 2.2 \\
\hline
\end{tabular}

Table 1 reveals that all the respondents consented to nursing process as the systematic collection of patient care data for determining nursing care needs and evaluating patient's care outcome, $275(98.9 \%)$ that the central purpose of nursing process is to diagnose and treat human responses to actual and potential health problems; assessment in nursing process is to find out actual and potential problems facing patients, and that nursing diagnosis is expressed as the concise statement of the problem, stating its relation to pathophysiology in the given situation and stating the way it is displayed/manifested by patient.

Table 2: Information on the level of Knowledge of Nurses about Nursing Process

\begin{tabular}{|l|l|c|c|}
\hline \multirow{2}{*}{ Knowledge level } & \multicolumn{2}{|c|}{ Category of scores } & \multicolumn{2}{|c|}{ Responses } \\
\cline { 3 - 4 } & & - & Freq \\
\hline Low & $0-3$ & 20 & 7.2 \\
\hline Average & $4-7$ & 258 & 92.8 \\
\hline High & $8-10$ & 278 & 100 \\
\hline Total & & \multicolumn{2}{|c|}{8.63} \\
\hline Mean & & \multicolumn{2}{|c|}{} \\
\hline Standard dev. & & \multicolumn{2}{|c|}{} \\
\hline
\end{tabular}

Table 2 presents the level of knowledge of nurses about nursing process. The respondents' knowledge level of nursing process was very high. The mean score was 8.63 which is equivalent to $86.3 \%$. Thus, it could be said that the level of knowledge of nurses about nursing process was high and adequate.

Table 3: Utilization of Nursing Process

\begin{tabular}{|l|l|c|c|c|c|c|}
\hline $\begin{array}{l}\text { S/ } \\
\mathbf{N}\end{array}$ & ITEMS & $\begin{array}{c}\text { Alway } \\
\mathbf{s}\end{array}$ & $\begin{array}{l}\text { Ofte } \\
\mathbf{n}\end{array}$ & Sometimes & Seldom & Never \\
\hline 1 & $\begin{array}{l}\text { I have been utilizing nursing process regularly } \\
\text { during admission of patients into my ward }\end{array}$ & $\begin{array}{c}272 \\
(97.8)\end{array}$ & $\begin{array}{c}6 \\
(2.2)\end{array}$ & - & - & - \\
\hline 2 & $\begin{array}{l}\text { I utilize nursing process to document nursing care } \\
\text { given to patients. }\end{array}$ & $\begin{array}{c}266 \\
(95.7)\end{array}$ & $\begin{array}{c}12 \\
(4.3)\end{array}$ & - & - & - \\
\hline 3 & $\begin{array}{l}\text { I have developed a nursing care plan of a patient in } \\
\text { the last one week. }\end{array}$ & $\begin{array}{c}236 \\
(84.9)\end{array}$ & $\begin{array}{c}21 \\
(7.6)\end{array}$ & $\begin{array}{c}12 \\
(4.3)\end{array}$ & 6 & 3 \\
$(2.2)$ & $(1.1)$ \\
\hline 4 & $\begin{array}{l}\text { Nursing process should be utilized occasionally } \\
(16.2)\end{array}$ & $\begin{array}{c}4 \\
(3.2)\end{array}$ & $\begin{array}{c}(1.1) \\
(6.5)\end{array}$ & $\begin{array}{c}(73.0) \\
(72)\end{array}$ \\
\hline 5 & $\begin{array}{l}\text { Once patients initial nursing diagnoses are solved, } \\
\text { there is no need to assess their response to other } \\
\text { health problems. }\end{array}$ & $\begin{array}{c}42 \\
(15.1)\end{array}$ & $\begin{array}{c}6 \\
(2.2)\end{array}$ & $\begin{array}{c}(1.1) \\
(3.2)\end{array}$ & $\begin{array}{c}(78.4) \\
(78)\end{array}$ \\
\hline 6 & $\begin{array}{l}\text { Nursing outcomes classification is regularly utilized } \\
\text { in my unit/ward. }\end{array}$ & $\begin{array}{c}223 \\
(80.2)\end{array}$ & $\begin{array}{c}31 \\
(11.2)\end{array}$ & $\begin{array}{c}9 \\
(3.2)\end{array}$ & $\begin{array}{c}6 \\
(2.2)\end{array}$ & $\begin{array}{c}9 \\
(3.2)\end{array}$ \\
\hline
\end{tabular}


The percentage $(\%)$ of the responses are in brackets.

Table 3 presents the utilization of nursing process among the participants. Utilizing nursing process regularly during admission of patients in their ward always $266(97.8 \%)$ topped the list of factors on the utilization of nursing process followed by utilization of nursing process to document nursing care given to patients 266 $(95.7 \%)$. Also, $236(84.9)$ of the nurses had developed a nursing care plan of a patient in the last one week while $223(80.2 \%)$ regularly utilized nursing outcomes classification in their unit/ward.

Table 4: Information on the level of Utilization of Nursing Process

\begin{tabular}{|l|l|c|c|}
\hline Knowledge level & \multicolumn{1}{|c|}{ Category of scores } & Freq & Responses \\
\cline { 2 - 4 } & & - & - \\
\hline Low & $1-10$ & 236 & 84.9 \\
\hline Average & $11-20$ & 42 & 15.1 \\
\hline High & $21-30$ & 278 & 100 \\
\hline Total & & \multicolumn{2}{|c|}{.192} \\
\hline Mean & & \multicolumn{2}{|c|}{} \\
\hline Standard dev. & & & 165 \\
\hline
\end{tabular}

Table 4 presents the level of utilization of nursing process among the respondents of the study. The participants' level of utilization of nursing process was on the average. Over two-third (89.9\%) of the nurses scored between 11 and 20 on the utilization scale. The implication of this is that their utilization level is on the average. The mean score of respondents' utilization of nursing process was 16.85 which is equivalent to $56.2 \%$. Thus, it could be said that the level of utilization of nursing process among the nurses that participated in this study is on the average.

Table 5: Summary of Multiple Regression Analysis of the influence of attitudinal factors on utilization of nursing process among nurses

\begin{tabular}{|c|c|c|c|c|c|c|}
\hline Model & $\mathbf{R}$ & R Square & Adjusted & Square & Std. Error of $t$ & stimate \\
\hline 1 & $.347^{\mathrm{a}}$ & .120 & & .117 & & 3.00821 \\
\hline & & & $\mathrm{OVA}^{\mathrm{a}}$ & & & \\
\hline Model & & Sum of Squares & df & Mean Square & $\mathbf{F}$ & Sig. \\
\hline Regression & & 342.038 & 1 & 342.038 & 37.797 & $.000^{\mathrm{b}}$ \\
\hline Residual & & 2497.616 & 276 & 9.049 & & \\
\hline Total & & 2839.655 & 277 & & & \\
\hline
\end{tabular}

a. Dependent Variable: Utilization

b. Predictors: (Constant), Attitudinal

Nurses' attitudinal factors yielded a coefficient of multiple regression $(R)$ of 0.347 and a multiple correlation square of .117 . This shows that $11.7 \%$ of the total variance in the utilization of nursing process among nurses is accounted for by attitudinal factors. The Table also indicates that the analysis of variance of the multiple regression data produced an F-ratio value (37.797) significant at 0.00 level $\left(\mathrm{R}=.347, \mathrm{R}^{2}=.120\right.$, Adj. $\mathrm{R}^{2}$ $\left.=.117, \mathrm{f}_{(1,277)}=37.797 ; \mathrm{P}=.000\right)$. Therefore, it could be said that nurses' attitude to nursing process will influence their utilization of nursing process among nurses.

Table 6: Summary of Multiple Regression Analysis of the influence of institutional factors on utilization of nursing process among nurses

\begin{tabular}{|c|c|c|c|c|c|c|}
\hline \multirow{2}{*}{$\begin{array}{l}\text { Model } \\
1 \\
\end{array}$} & $\mathbf{R}$ & R Square & \multicolumn{2}{|c|}{$\begin{array}{c}\text { Adjusted R } \\
\text { Square }\end{array}$} & \multicolumn{2}{|c|}{ Std. Error of the Estimate } \\
\hline & $.285^{\mathrm{a}}$ & .081 & & .078 & & 4.16574 \\
\hline \multicolumn{7}{|c|}{ ANOVA $^{a}$} \\
\hline Model & & Sum of Squares & df & Mean Square & $\mathbf{F}$ & Sig. \\
\hline & Regression & 424.760 & 1 & 424.760 & 24.477 & $.000^{\mathrm{b}}$ \\
\hline & Residual & 4789.545 & 276 & 17.353 & & \\
\hline & Total & 5214.306 & 277 & & & \\
\hline
\end{tabular}

a. Dependent Variable: Institutional

b. Predictors: (Constant), Utilization

Institutional factors yielded a coefficient of multiple regression $(\mathrm{R})$ of 0.285 and a multiple correlation square of .078 . This shows that $7.8 \%$ of the total variance in the utilization of nursing process among nurses is accounted for by institutional factors. The Table also indicates that the analysis of variance of the multiple regression data produced an F-ratio value (24.477) significant at 0.00 level $\left(\mathrm{R}=.285, \mathrm{R}^{2}=.081\right.$, Adj. $\mathrm{R}^{2}=.078$, $\left.\mathrm{f}_{(1,277)}=37.797 ; \mathrm{P}=.000\right)$. Therefore, it could be said that factors within the institutions will influence nurses' utilization of nursing process among nurses. 
Table 7: Summary of Multiple Regression Analysis of the influence of knowdge on utilization of nursing process among nurses

\begin{tabular}{|c|c|c|c|c|c|c|}
\hline Model & $\mathbf{R}$ & R Square & $\begin{array}{r}\text { Adjust } \\
\text { Squa } \\
\end{array}$ & \multicolumn{3}{|c|}{ Std. Error of the Estimate } \\
\hline 1 & $.194^{\mathrm{a}}$ & .038 & & .034 & & 3.14645 \\
\hline \multicolumn{7}{|c|}{ ANOVA $^{\mathbf{a}}$} \\
\hline \multirow[t]{4}{*}{ Model } & & Sum of Squares & df & Mean Square & $\mathbf{F}$ & Sig. \\
\hline & Regression & 107.215 & 1 & 107.215 & 10.830 & $.001^{\mathrm{b}}$ \\
\hline & Residual & 2732.440 & 276 & 9.900 & & \\
\hline & Total & 2839.655 & 277 & & & \\
\hline
\end{tabular}

a. Dependent Variable: Knowledge

b. Predictors: (Constant), Utilization

Knowledge yielded a coefficient of multiple regression (R) of 0.194 and a multiple correlation square of .034. This shows that $3.4 \%$ of the total variance in the utilization of nursing process among nurses is accounted for by knowledge. The Table also indicates that the analysis of variance of the multiple regression data produced an F-ratio value (10.830) significant at 0.00 level $\left(\mathrm{R}=.194, \mathrm{R}^{2}=.038\right.$, Adj. $\mathrm{R}^{2}=.034, \mathrm{f}_{(1,277)}=$ $10.830 ; \mathrm{P}=.001)$. Therefore, it could be said that nurses knowledge of nursing process will influence their utilization of nursing process.

Table 8: Summary of Multiple Regression Analysis of relative and composite influence of nurses' sociodemographic characteristics (age, gender, professional qualifications, professional cadre, and years of working experience) on utilization of nursing process among nurses

\begin{tabular}{|c|c|c|c|c|c|}
\hline \multirow[t]{2}{*}{ Model } & \multicolumn{2}{|c|}{ Unstandardized Coefficients } & \multirow{2}{*}{$\begin{array}{c}\begin{array}{c}\text { Standardized } \\
\text { Coefficients }\end{array} \\
\text { Beta }\end{array}$} & \multirow[t]{2}{*}{$\mathbf{t}$} & \multirow[t]{2}{*}{ p-value } \\
\hline & Std. & Error & & & \\
\hline (Constant) & 14.763 & 1.386 & & 10.652 & .000 \\
\hline Age & .278 & .266 & .083 & 1.045 & .297 \\
\hline Gender & .997 & .561 & .108 & 1.777 & .077 \\
\hline Prof. qualification & -.053 & .256 & -.013 & -.208 & .836 \\
\hline Prof. Cadre & -.044 & .159 & -.028 & -.277 & .782 \\
\hline Yrs of experience & -.132 & .192 & -.069 & -.688 & .492 \\
\hline Source of variation & Sum of Squares & Df & $\begin{array}{c}\text { Mean } \\
\text { Square }\end{array}$ & F-Ratio & $\mathbf{P}$ \\
\hline Regression & 50.968 & 5 & 10.194 & .994 & $.422^{b}$ \\
\hline Residual & 2788.687 & 272 & 10.253 & & \\
\hline Total & 2839.655 & 277 & & & \\
\hline
\end{tabular}

$R=0.134 ; \quad$ Multiple $R=0.018 ;$ Multiple $R^{2}$ (Adjusted) $=0.000 ;$ Stand error estimate $=3.202$

The relative contribution of each predictor variable (age, gender, professional qualifications, professional cadre, and years of working experience) to the variance in the utilization of nursing process among nurses revealed that all the predictors failed to significantly influence the utilization of nursing process. Therefore, age, gender, professional qualifications, professional cadre, and years of working experience were found not to influence the utilization of nursing process among nurses.

\section{Discussion of Findings}

The outcome of this study showed that the level of knowledge of nurses about nursing process was very high. For instance, all the respondents consented to nursing process as the systematic collection of patient care data for determining nursing care needs and evaluating patient's care outcome, almost $99 \%$ agreed that the central purpose of nursing process is to diagnose and treat human responses to actual and potential health problems; assessment in nursing process is to find out actual and potential problems facing patients, and that nursing diagnosis is expressed as the concise statement of the problem, stating its relation to pathophysiology in the given situation and stating the way it is displayed/manifested by patient as evidenced by.

The high knowledge level reported by the nurses is in support with the assertion of Agyeman-Yeboah and Korsah (2016) who highlighted that the knowledge of nurses on the nursing process is necessary for a nurse to be able to develop skills in diagnostic reasoning which, in turn, will enhance their easy use of the nursing process in the management of their patients. Also, the outcome of research question one is similar to the studies conducted by Agunwah, (2010), Akbari and Farmahini (2011), Agyeman-Yeboah and Korsah (2016) revealed that majority of their participants took a course in the nursing process during their training. Although the findings from these studies revealed that most nurses have acquired some form of knowledge on the nursing process. The implication of this findings is that adequate education on application of the nursing process helps in developing nursing 
science and increasing nurses' participation in promoting the quality of the care given to the patient.

Results of this study indicated the level of utilization of nursing process among the nurses that participated in this study was on the average. However, $97.8 \%$ utilized nursing process regularly during admission of patients in their ward, $95.7 \%$ always utilized nursing process to document nursing care given to patients, and $84.9 \%$ of the nurses had developed a nursing care plan of a patient in the last one week. This finding correspond to those realized in a study to evaluate utilization of nursing process among nurses in a Psychiatric hospital in Port Harcourt (Nigeria)whereby the nurses' practice on nursing process was found to be poor (Afolayan, Donald, Baldwin, Onasoga \& Babafemi, 2013). Likewise, a review of 68 medical records at a Brazilian teaching hospital showed that all the steps of nursing process were not documented (Lopes, Higa, Christoforo, Oliveira\& Reis, 2010).These findings were in concurrence with those of a study on professional nurses' perception of the nursing process at the University of Calabar Teaching Hospital, Nigeria which showed that $62.7 \%$ of the respondents were constantly using the NANDA diagnostic system, with $25.4 \%$ using it occasionally while $11.9 \%$ never used it at all. Another study conducted among 249 nurses from five selected health care facilitiesin Kenya, the study results showed that utilization of nursing process among the respondents was poor (Mbithi, Mwenda, \& Karonjo, 2018)

Results revealed that $11.7 \%$ of the total variance in the utilization of nursing process among nurses is accounted for by attitudinal factors. Therefore, it could be said that nurses' attitude to nursing process will influence their utilization of nursing process among nurses. This could be that "most nurses are resistant to change, professional development and advancement. Some nurses tend to hold onto previous knowledge and skills without making efforts to improve and maintain new skills. Many nurses are not willing to accept the challenges of staying abreast with education and development of new skills in nursing practice. This corroborates the findings of Akbari and Shamsi (2011) that attitudinal factors include insufficient information, no belief in doing the patient care according to it, lack of sufficient motivation in doing Nursing Process, lack of enough skill for doing Nursing Process, uninteresting in doing the Nursing Process, and lack of cooperation among the nurses. Also, Anyasor and Alowolodu (2017) found that on the aspect of nurses attitude towards the utilization of nursing process, both positive and negative attitude were observed. More than half of the respondents strongly believed that nursing process plays an important role in practice; hence they are willing to apply nursing process in the care of their patients because it enabled them to provide quality care which in turn improved the outcome of care.

Results indicated a $7.8 \%$ total variance in the utilization of nursing process among nurses is accounted for by institutional factors. Therefore, it could be said that factors within the institutions will influence nurses' utilization of nursing process among nurses. This result is line with that of Adeyemo and Olaogun, (2013) that assessed the factors affecting the utilization of nursing process and revealed that institutional factors affected utilization of nursing process. The implication of this is that the institutional factors may be repetitious replacement of the nurses, shortage of nursing staff, no format for writing, lack of monitoring on nursing process, inadequate facilities, insufficient time, lack of attention to its importance, lack of specific instructions, lack of education, lack of enough trained nurses, and hospital policies not favouring implementation of the nursing process. This is equally supported by Mangare, Omondi, Ayieko, Wakasiaka, and Wagoro (2016).

Results indicated a $3.4 \%$ total variance in the utilization of nursing process among nurses is accounted for by institutional factors. It could be said that nurses knowledge of nursing process will influence their utilization of nursing process. This is in tandem with the findings that nurses knowledge has direct statistically significant relationship with the utilization of nursing process. Mahmoud and Bayoumy (2014) observed that nurses' level of knowledge was statistically associated with utilization of nursing process. More so, nurses' lack of previous knowledge or experience as regards to the nursing process lead to the resistance of its application as nurses may think that its implementation in practice demands a complex and rigorous process which is often time consuming and not feasible (Brandalize \& Kalinowski, 2015).

The outcome of this study revealed that age, gender, professional qualifications, professional cadre, and years of working experience did not influence the utilization of nursing process among nurses. This contradicts the previous findings of Mahmoud and Bayoumy (2014) who observed that socio-demographic characteristics of nurses like age, gender, years of work experience, level of education, professional cadre have significant impact on nursing process utilization. Also, Afoi et al (2012) found significant difference in the level of implementation of the process across units such as medical, surgical, obstetrics and gynaecology, pediatrics and special unit based on socio-demographics.

\section{Conclusion}

Effective and efficient implementation of the nursing process directly contributes to the quality of healthcare and the patients' health outcomes. From the findings in this study it can be concluded that the influence of nurses' knowledge, attitude, and institutional factors on adequate and proper utilization of nursing process cannot be jettisoned. Therefore, the nurses' knowledge, attitude, and institutional factors are core in the proper utilization 
of nursing process. In this study, the influence of socio-demographic characteristics of age, gender, professional qualifications, professional cadre, and years of working experience were found not to have any positive influence on utilization of nursing process among nurses.

\section{References}

Abebe, N., Abera, H., \& Ayana, M. (2014). The implementation of nursing process and associated factors among nurses working in Debremarkos and Finoteselam Hospitals, Northwest Ethiopia, 2013. J Nurs Care, 4-7.

Adeyemo, F. O., \& Olaogun, A. A. A. F. (2013). Factors affecting the use of nursing process in health institutions in Ogbomoso town, Oyo State. Int J Med Pharmacol Sci, 1, 191-98.

Afoi, B. B., Emmanueul, A., Garba, S. N., Gimba, S. M., \& Afuwai, V. (2012). Evaluation of the implementation of nursing process among nurse clinicians. Continental J. Nursing Science 4 (1): $34-46$.

Afolayan, J. A., Donald, B., Baldwin, D. M., Onasoga, O., \& Babafemi, A. (2013). Evaluation of the utilization of nursing process and patient outcome in psychiatric nursing: case study of psychiatric hospital Rumuigbo, Port Harcourt, Nigeria. Advances in Applied Science Research, 4(5), 34-43.

Agunwah, E. (2010). Evaluation of implementation of nursing process among nurses in Enugu. West African journal of nursing, 21(2), 8-14.

Agyeman-Yeboah, J. O. A. N. A., \& Korsah, K. A. (2016). Determinants of clinical utilizations of the nursing process by nurses: a study at the 37 Military Hospital, Accra. International Journal of General Medicine and Pharmacy (IJGMP), 5(6), 1-23.

Akbari Kaji, M., \& Farmahani Farahani, B. (2011). The effect of nursing process education on nursing care quality of schizophrenic patients. KAUMS Journal (FEYZ), 15(1), 32-37.

Akpan-idiok, P. A. (2017). Knowledge and Practice of nursing process among nurses in University of Calabar Teaching Hospital, Cross river State, Nigeria. World Journal of Pharmaceutical and Medical Research, $3(1), 296$.

Anyasor, C. O., \& Oluwatoyin, A. Nurses' Knowledge, Attitude And Perceived Barrier Towards The Implementation Of Nursing Process At A General Hospital In Lagos State, Nigeria. Age, 21(30), 31-40.

Aseratie, M., Murugan, R., \& Molla, M. (2014). Assessment of factors affecting implementation of nursing process among nurses in selected governmental hospitals, Addis Ababa, Ethiopia; Cross Sectional Study. $J$ Nurs Care, 3(3), 170.

Baraki, Z., Girmay, F., Kidanu, K., Gerensea, H., Gezehgne, D., \& Teklay, H. (2017). A cross sectional study on nursing process implementation and associated factors among nurses working in selected hospitals of Central and Northwest zones, Tigray Region, Ethiopia. BMC nursing, 16(1), 54.

Brandalize, D. L., \& Kalinowski, E. C. (2005). Nursing process: experience in the implementation of the diagnostic phase. Cogitare Enferm, 10(3), 53.

Donkor, N. (2009) Challenges and Opportunities of the 21st Centaury Nursing Practice in Ghana. A paper presented at the International Conference of Nursing, Accra, Ghana.

Lopes MH, Higa R, Christoforo FF, Oliveira RN, Reis MJ, (2010). Evaluation of the nursing process used at a Brazilian teaching Hospital; International Journal of Nursingterminologies and classifications; 21(3)116123.

Mahmoud, M. H., \& Bayoumy, H. M. (2014). Barriers and facilitators for execution of nursing process from nurses' perspective. International Journal of Advanced Research, 2(2), 300-315.

Mangare, N. L., Omondi, A. L., Ayieko, O. A., Wakasiaka, S., \& Wagoro, M. C. (2016). Implementation of the Nursing Process in Naivasha District Hospital, Kenya. American Journal of Nursing, 5(4), 152-157.

Mbithi, B. W., Mwenda, C. S., \&Karonjo, J. (2018). Observed Utilization of the Nursing Process among Nurses in Selected Public Health Care Facilities in Kenya. International Journal of Nursing, 8(5), 77-82.

Ofi, B., Sowunmi, L., Edet, D., \& Anarado, N. (2008). Professional nurses' opinion on research and research utilization for promoting quality nursing care in selected teaching hospitals in Nigeria. International Journal of Nursing Practice, 14(3), 243-255.

Ojo, A. A. (2010). The challenges of best practices and standards in nursing in Nigeria. Igbinedion University, Edo State Inaugural Lecture Series, 4th Igbinedion University Press, Okada.

Pokorski, S., Moraes, M. A., Chiarelli, R., Costanzi, A. P., \& Rabelo, E. R. (2009). Nursing process: from literature to practice. What are we actually doing?. Revista Latino-Americana de Enfermagem, 17(3), 302307. 